\title{
Spatial Distribution of Soybean Cyst Nematode in Research Plots
}

\author{
Susilo H. Poromarto, ${ }^{1}$ Luis E. del Río Mendoza, ${ }^{2}$ and Berlin D. Nelson, Jr. ${ }^{2, \dagger}$ \\ ${ }^{1}$ Agrotechnology, Sebelas Maret University, Surakarta, Indonesia \\ ${ }^{2}$ Department of Plant Pathology, North Dakota State University, Fargo, ND 58102, U.S.A.
}

\begin{abstract}
Soybean cyst nematode (SCN; Heterodera glycines Ichinohe) is a major pathogen of soybean [Glycine max (L.) Merr.] in the United States. The spatial distribution of SCN in 10 naturally infested research sites in North Dakota was examined between 2006 and 2009. Egg densities were measured in plots and expressed as arithmetic means or grouped into classes using two categorical scales based on the effect of SCN on yield. Data were used to determine spatial distribution, egg cluster sizes, minimum plot sizes, and replications in field experiments. SCN populations varied among plots from undetected to $25,800 \mathrm{eggs} / 100 \mathrm{~cm}^{3}$ of soil, and

differences between adjacent plots were as high as sixfold. Mean to median ratios and Lloyd's index of patchiness suggested an aggregated distribution in nine of the 10 sites. SCN cluster sizes varied in five of the 10 sites and optimum plot size over all sites varied depending on calculation methods. The minimum number of replications needed to detect specific differences among plots varied between field sites. Grouping data into either of the two categories generally increased the ability to detect differences between plots. The spatial distribution of SCN can be a critical factor affecting design and outcomes of field experiments.
\end{abstract}

Soybean [Glycine $\max$ (L.) Merr.] is one of the most important crops in the United States. In 2017 the crop was planted on 36.2 million ha, producing approximately 119.6 million metric tons (U.S. Department of Agriculture 2019). In North Dakota, soybean was planted on 2.9 million ha in 2017. Soybean cyst nematode (SCN), Heterodera glycines Ichinohe (Tylenchida: Heteroderidae), is the most important pathogen of soybean (Allen et al. 2017). The nematode has numerous hosts, such as soybean, dry bean, lupine, sweet clover, and chickweed, and is widely adapted to various environments and agricultural conditions (Pedersen et al. 2010; Poromarto and Nelson 2009, 2010; Riggs and Hamblen 1962). SCN can reproduce wherever there are host plants, and the nematode is able to survive under various environmental stresses such as low temperature (Duan et al. 2009). Since SCN was first reported in 1954 in North Carolina (Winstead et al. 1955), the nematode has been documented in more than 30 states and Canada with the intensification of soybean cultivation (Tylka and Marett 2017). In North Dakota, SCN was first reported in 2003 (Bradley et al. 2004).

Studies on the spatial distribution of SCN have been conducted primarily to gain information useful in the development of disease management systems. Most studies have been conducted in large field areas and the spatial distribution has been described as aggregated (Gavassoni et al. 2001; Kulkarni et al. 2008; Melakeberhan et al. 2004). The study of spatial distribution of SCN in small $\left(<15 \mathrm{~m}^{3}\right)$ field plots, such as those used to compare performance of soybean varieties, has received limited attention. Francl (1986a) examined SCN distribution in a research field plot to obtain more precise sampling procedures for field experiments. Francl (1986a) estimated that the optimum plot length for minimal spatial heterogeneity in four-row mechanically tended field plots was $6 \mathrm{~m}$ after

${ }^{\dagger}$ Corresponding author: B. D. Nelson, Jr.; berlin.nelson@ ndsu.edu

Funding: This research was supported by the North Dakota Soybean Council and the National Institute of Food and Agriculture Hatch project ND02223.

*The $\boldsymbol{e}$-Xtra logo stands for "electronic extra" and indicates that two supplementary figures are published online.

The author(s) declare no conflict of interest.

Accepted for publication 6 February 2019.

() 2019 The American Phytopathological Society trimming plot ends, and he suggested taking at least 20 soil cores to obtain an adequate sample representing the population density at the beginning of the season after plowing (Francl 1986b). PérezHernández and Giesler (2017) studied intra- and interplot variability of SCN population densities in three experimental plots in Nebraska over one season. They reported one site with a random pattern of SCN incidence and the other two sites with an aggregated pattern within plots. Their study clearly showed that incidence of SCN within plots and population densities among plots can be in a clustered pattern and how that could affect soybean variety trials comparing reactions to SCN. They further point out the importance of the spatial pattern of SCN to site suitability and the methodology used to conduct field studies with SCN.

Nematode egg density and spatial distribution usually are unknown before field experiments begin, and it is generally not practical to create plots with uniform egg distribution. Furthermore, egg density and spatial distribution cannot be estimated based on symptoms on the previous crop. Up to $30 \%$ yield losses have been observed on susceptible compared with resistant cultivars in areas of fields heavily infested with SCN without any differences in plant height or chlorosis between the cultivars (Niblack 2005). Knowledge of the spatial distribution of nematodes is important in understanding their biology, in devising sampling programs, and in understanding the results from research plot studies. In preliminary research in North Dakota when testing cultivars for resistance to SCN under field conditions, large differences in egg densities were noted between research plots. Because these differences could affect the results from research conducted under field conditions, an in-depth examination of the spatial distribution of egg densities in research size areas in naturally infested fields was conducted. The objectives of this study were as follows: (i) to measure $\mathrm{SCN}$ egg population density in two- to four-row field plots and analyze the spatial distribution of $\mathrm{SCN}$ in a number of research field sites, (ii) to calculate the minimum research plot size using various criteria, and (iii) to determine minimal plot replications for a site. In addition to continuous data, categorical data were employed to examine each of these objectives. A preliminary report of this research was published previously (Poromarto et al. 2011)

\section{Materials and Methods}

Field sites. Ten research sites were established between 2006 and 2009 in fields naturally infested with SCN. These sites had histories of soybean production and SCN. All sites were used for evaluating soybean cultivars for yield in the presence of SCN. This study used 
the plots in those sites to examine spatial distribution of SCN. The research sites were designated A through J. Site J was in Cass County, near Arthur, North Dakota, and all of the others were in Richland County, in the area between Dwight and Mooreton, North Dakota. The following groups of sites were in the same 65-ha fields, but each year the research site was located in a different part of the field: A, C, E, and H; B, D, and F; and G and I. The research sites ranged from 557 to $975 \mathrm{~m}^{2}$. The soil classes for these field sites were the following: Arveson loam (sites A, C, E, and H), Wyndmere loam (sites B, D, and F), Galchutt-Wheatville silt loam (sites G and I), and Glyndon-Tiffany silt loam (site J).

Research in sites A and B was conducted in 2006 and the two sites contained 96 and 72 plots, respectively. Plots were $6.9 \mathrm{~m}^{2}$ and contained four plant rows, $4.55 \mathrm{~m}$ long with $38-\mathrm{cm}$ spacing between rows. Sites C and D were established in 2007 and contained 75 plots each. Plots were $9 \mathrm{~m}^{2}$ and contained four rows, $3 \mathrm{~m}$ long and spaced $76 \mathrm{~cm}$ apart. Sites E, F, and G each had 40 plots and sites H, I, and J each had 28 plots and were established in 2008 and 2009, respectively. The plot size in sites E, F, G, H, I, and J was $6.4 \mathrm{~m}^{2}$, containing two rows, $4.2 \mathrm{~m}$ long with $76-\mathrm{cm}$ spacing between rows. The plot size used in each field experiment is referred to as the basic unit.

Determining egg densities. The SCN egg density in each plot was assessed within 2 weeks after planting, which occurred during the last 2 weeks of May. Oakfield soil probes (20-mm-diameter core; Oakfield Apparatus, Oakfield, WI) were used to sample the soil to a depth of $15 \mathrm{~cm}$. In sites A through D, three soil cores were taken at arbitrary locations along the length of each row for 12 soil cores per plot. In all of the other sites, five soil cores were taken in a similar way along the two inside rows for 10 soil cores per plot. Soil cores from each plot were broken up by hand, air dried, and then mixed for $1 \mathrm{~min}$ in a Twin Shell dry blender (1 cu ft; Keith Machinery Corporation, Lindenhurst, NY). The soil was then processed to determine egg densities.

To extract SCN, soil was processed as follows: (i) soil $\left(100 \mathrm{~cm}^{3}\right)$ was placed into $2,400 \mathrm{ml}$ of water, and then stirred vigorously to break up any clumps and mix the cysts into a suspension; (ii) coarse soil particles were allowed to settle out for $4 \mathrm{~s}$, and the supernatant was poured over an 18-mesh sieve (1-mm pore) to filter out larger debris and the elutriate was collected; (iii) the supernatant was then poured over a 60 -mesh sieve $(250 \mu \mathrm{m})$, which retained cysts; and (iv) the cysts on the 60-mesh screen were then crushed in water with a Wheaten Potter Elvehjem Tissue Grinder (55-ml capacity) and the eggs were collected by pouring the suspension over a 200 -mesh screen ( $75-\mu \mathrm{m}$ pore) nested over a 500 -mesh screen $(25-\mu \mathrm{m}$ pore). The eggs on the 500-mesh sieve were collected in $50 \mathrm{ml}$ of water and the eggs in two separate 1-ml aliquots were counted with a compound microscope. The average of the two samples was calculated and the egg density per $100 \mathrm{~cm}^{3}$ of soil was determined.

Calculating mean egg density. Four methods of expressing mean egg density were used. The first method consisted of calculating the arithmetic mean using raw egg density numbers. In the second method, the mean was transformed with $\log _{10}(x+1)$ (transformed mean egg density). In the third and fourth methods, readings of raw egg densities were grouped into six and four different categories, designated as GD1 and GD2, respectively. In both GD1 and GD2, the median of the data in each category was determined and used to represent the egg density for each plot. The median, rather than the midpoint of the category, was used to reduce data variance.

GD1 was established following the classification suggested by Hershman (2010), which considers the egg density levels at which susceptible compared with resistant cultivars would potentially be affected by SCN. GD1 categories were as follows (in number of eggs/ $100 \mathrm{~cm}^{3}$ of soil): 0 , eggs not detected (0); 1 , very low (1 to 200); 2 , low (201 to 400$) ; 3$, moderate (401 to 1,200$)$; 4 , high $(1,201$ to $2,000)$; and 5 , very high $(\geq 2,001)$.

The four categories used in the GD2 scale were based on a scale published by Tylka (2012) for SCN management in Iowa. The rationale for the scale was similar to the Hershman scale but with only four egg density categories. GD2 categories were as follows (in number of eggs $/ 100 \mathrm{~cm}^{3}$ of soil): 0 , no eggs detected (0); 1 , low (1 to 2,000$) ; 2$, moderate $(2,001$ to 12,000$)$; and 3 , high $(\geq 12,001)$.

Spatial distribution and cluster sizes in field plots. The spatial distribution of SCN eggs in each site was characterized using three approaches: Lloyd's index of patchiness (LIP) (Lloyd 1967), mean to median ratio (MMR), and correlations between the absolute number of 1 - MMR and LIP. LIP was calculated as follows:

$$
\mathrm{LIP}=1+\left[\frac{\left(s^{2}-m\right)}{m^{2}}\right]
$$

where $m$ and $s^{2}$ are the mean and the variance of the sample values, respectively. If LIP equals 1 , the distribution will be considered to be at random; if LIP is greater than 1, the distribution will be considered to be aggregated; and when LIP is $<1$, the distribution will be considered to be uniform. LIP indices were calculated using the untransformed mean egg density and the GD1 and GD2 data that were transformed with $\log _{10}(x+1)$. MMRs for egg densities were calculated for each site using untransformed raw egg density data. Correlations between absolute number of 1 - MMRs and LIPs were conducted using PROC CORR in the Statistical Analysis System (version 9.4; SAS Institute, Cary, NC)

Cluster sizes were calculated for sites A, B, C, D, E, F, and G by using the quadrat variance method (Campbell and Madden 1990). The transformed mean egg density and the data grouped into two different categories (GD1 and GD2) were used for these calculations. GD1 and GD2 data were transformed with $\log _{10}(x+1)$. Sites H, I, and $\mathrm{J}$ were not included in the calculations because they had too few data points. The variances were calculated for successively larger blocks of sample quadrat counts collected from a grid of contiguous quadrats. The stepwise increase in quadrat size was through doubling the previous plot size. The peak of maximum variance was determined to be the cluster size.

Optimum plot size. Optimum plot size was defined as the smallest plot size at which point the variance stabilized. Two methods were employed to estimate optimum plot size, using the transformed mean egg density and the transformed data from categories GD1 and GD2. First, comparable variance methods (CVMs), as suggested by Keller (1949), were used. The formula was as follows:

$$
V=V_{x} / X^{2}
$$

where $V$ is the variance of a unit plot, $V_{x}$ is variance (on a per unit basis) of plots formed from adjacent units, and $X$ is the plot size in multiples of adjacent unit plots.

At each site, the original plot size (the basic unit) was considered to be $100 \mathrm{RI}$, where RI indicates relative information. First, the variance over all plots at a site was calculated. As plot size increased, the variance was determined again and RI was calculated by dividing the variance of the basic unit by the variance of the increased plot size. RI then was plotted against plot size. With each increase in plot size, RI was calculated again. The optimum plot size was determined when RI decreased rapidly to a point where there was almost no change detected after that point.

Second, the maximum curvature technique (MCT), as modified by Leilah and Al-Barrak (2005), was used. In this technique, the coefficient of variability $(\mathrm{CV})$ was plotted against the increase in plot size. The point of maximum curvature $\left(X_{\mathrm{o}}\right)$ on the graph $\left(\mathrm{CV}=A X^{-\mathrm{b}}\right)$ was determined as the optimum plot size using the following equation:

$$
X_{0}=\frac{A^{2} B^{2}(2 B+1)}{(B+2)^{\frac{1}{(2 B+2)}}}
$$

where $X_{0}$ is the optimum plot size (in basic units), $A$ is the intercept, and $B$ is the slope.

Convenience plots. Convenience plots are plots of a certain size and number of replications required to detect a difference of a specified size. Convenience plots were estimated for each site according to the methods developed by Hatheway (1961). The transformed mean egg density and the transformed data from GD1 and GD2 were used in the following equation: 


$$
X^{b}=\frac{2 \times\left(t_{1}+t_{2}\right)^{2} \mathrm{CV}^{2}}{r d^{2}}
$$

where $X$ is the number of basic units, $b$ is Smith's index of soil variability, $t_{1}$ is the significant value of $t$ in the test with 30 degrees of freedom $(d f), t_{2}$ is the value of $t$ in the table corresponding to $2 d f$ and probability $=(1-P)$ (where $P$ is the probability of obtaining a significant result at 15\%), $r$ is the number of replications, and $d$ is the percentage of the mean of difference to be detected.

The Smith's soil variability index was calculated from $V_{x}=V / X^{b}$, where $V$ is the variance of the unit plot, $V_{x}$ is the variance (on a per unit basis) of a plot formed from adjacent units, and $X$ is plot size in multiples of adjacent unit plots.

\section{Results}

Egg densities and spatial distribution. Egg densities of SCN varied within and among research sites (Fig. 1; Table 1). Within research sites, egg densities ranged from undetected levels to 6,500, 16,250, and 20,750 eggs in site C, A, and D, respectively. In site G, egg densities ranged from 2,200 to 25,800 . Site $\mathrm{E}$ had the highest mean egg density, with $7,840 \mathrm{eggs} / 100 \mathrm{~cm}^{3}$ of soil; site $C$ had the lowest overall mean density at $951 \mathrm{eggs} / 100 \mathrm{~cm}^{3}$.
A

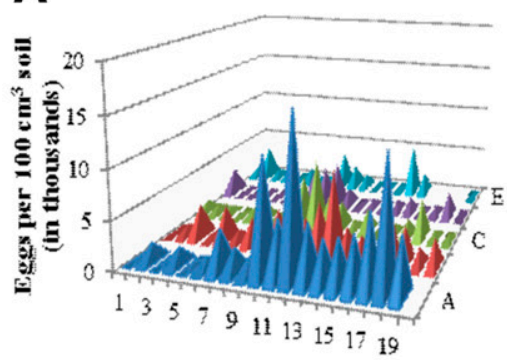

D
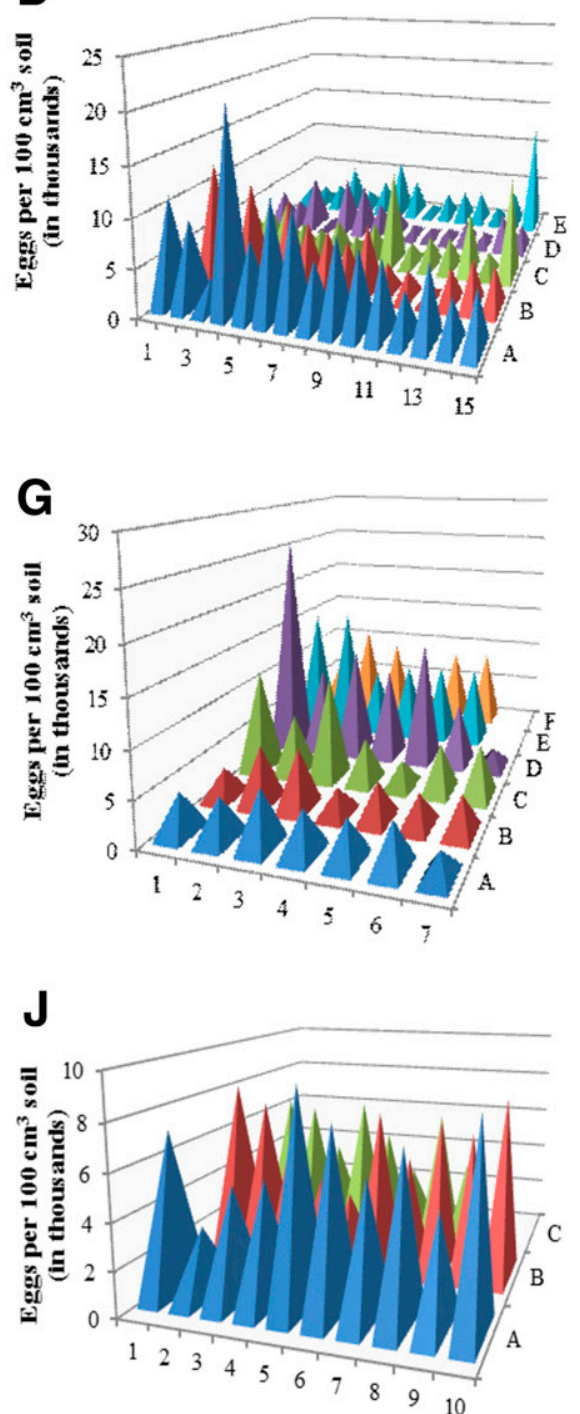

B

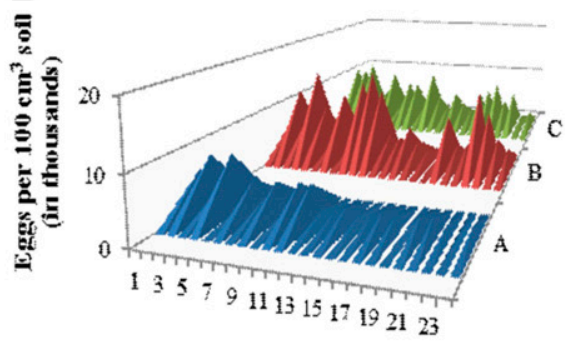

C

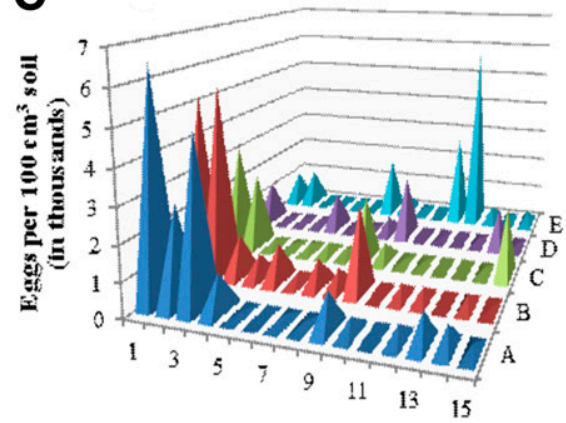

E

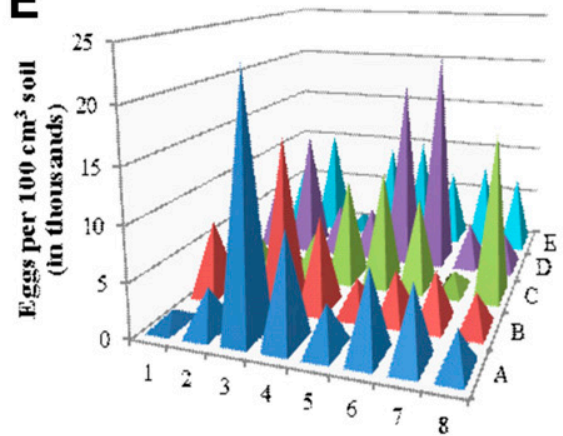

H

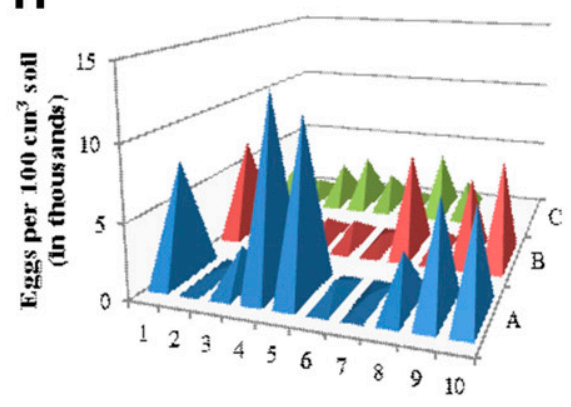

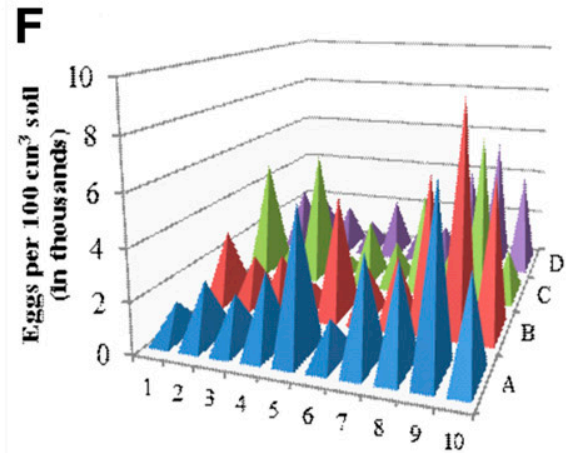

I

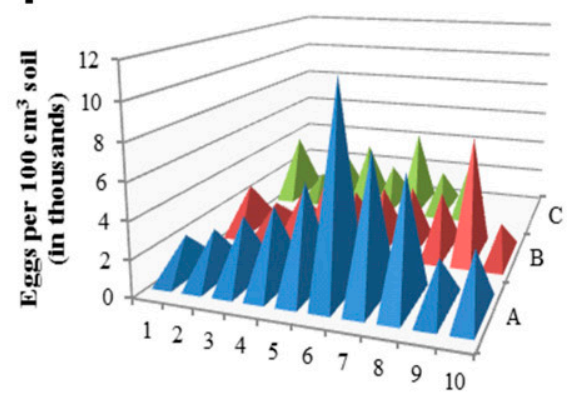

Fig. 1. A to J, Spatial distribution of soybean cyst nematode eggs in individual research plots in 10 different field experiments, respectively. The numbers and letters indicate plots and ranges, respectively. The plot sizes were as follows: sites $\mathbf{A}$ and $\mathbf{B}, 6.9 \mathrm{~m}^{2} ; \mathbf{C}$ and $\mathbf{D}, 9 \mathrm{~m}^{2}$; and $\mathbf{E}, \mathbf{F}, \mathbf{G}, \mathbf{H}, \mathbf{I}$, and $\mathbf{J}, 6.4 \mathrm{~m}^{2}$. 
In all sites but $\mathrm{J}$, the mean numbers of eggs (raw data) were greater than the median (Table 1). Using untransformed data, the LIPs for sites ranged from 1.0 to 3.3 (Table 1). The numerical ranking of the LIPs among the three methods of determining mean egg density were similar, with site $\mathrm{C}$ having the highest LIP, followed by site A; site $\mathrm{J}$ had the lowest LIP. The sites with the lowest mean egg density tended to have greater LIPs. The MMRs ranged between 0.98 and 2.72 (Table 1). There was a strong correlation $(r=0.97,0.96$, and 0.95 for untransformed data, GD1, and GD2, respectively; $P<$ 0.0001 ) between the absolute value of 1 - MMR and LIP, which implied that the greater the absolute number of 1 - MMR, the more aggregated the spatial distribution.

Cluster size. SCN cluster size was calculated for seven of the 10 sites (Fig. 2; Table 2). In sites H, I, and J, there were insufficient samples to determine cluster size. Using the transformed GD1 data, the cluster size in site $\mathrm{G}$ could not be calculated because all data were in one of the six categories. Cluster size in sites A and C could not be determined using transformed egg density data or categorical transformed data (Fig. 2), and cluster size could not be determined when calculated using transformed data in site F. Using transformed egg density data or categorical transformed data produced SCN clusters of similar sizes in sites D and E. However, in site B, they were not similar in size. In site F, cluster sizes were similar when calculated using transformed grouped data. Cluster sizes were $26 \mathrm{~m}^{2}$ (four basic units) in sites E and G, $72 \mathrm{~m}^{2}$ in site D (eight basic units), and $55 \mathrm{~m}^{2}$ (eight basic units) and $28 \mathrm{~m}^{2}$ (four basic units) in ungrouped and grouped data in site $\mathrm{B}$, respectively. There was no correlation between cluster size and LIP $(r=0.04)$.

Optimum plot size, replications, and convenience plot size. The SCN optimum plot size was calculated for nine of the 10 sites (Table 2). The optimum plot size over all sites ranged between 2 to 4 times and 0.36 to 6.12 times larger than the basic plot size used in the experiment when calculated with CVM and MCT, respectively (Table 2). For example, at site A, the optimum plot size was $28 \mathrm{~m}^{2}$ using the CVM method and any of the three data sets, which was four times larger than the $7 \mathrm{~m}^{2}$ plots used in the experiment. For site $C$, the optimum plot size was estimated to be $45 \mathrm{~m}^{2}$ using the MCT method, which was five times larger than the $9 \mathrm{~m}^{2}$ used as the plot size. The optimum plot size could not be calculated in site $\mathrm{G}$ when using data grouped into six categories (GD1) or in site $\mathrm{J}$ for either categorical data set, owing to the fact that all data fell into one category.

The data set, whether categorical or based on transformed mean egg count, used to calculate optimum plot sizes with the CVM method did not influence the final outcome. The optimum plots were of similar size. However, when using the MCT method, the sizes of optimum plots were more variable. For example, site E had an optimum plot size about twice as large using the transformed mean egg density compared with the grouped data. Conversely, the optimum plot size with the MCT method in site B was about $40 \%$ larger when calculated with the transformed mean egg density compared with the grouped data. The minimum number of plots (i.e., replications) needed to compensate for the aggregated pattern of spatial distribution was lower when using categorical data. The relationship between plot sizes, number of replications, and percentage of detectable differences for all fields are presented in Supplementary Figures S1 and S2. In general, grouping data into either of the two category groups (GD1 and GD2) resulted in smaller minimum plot sizes and fewer replications and increased our ability to detect differences between plots. For example, in site B, using the transformed egg density to detect a $15 \%$ difference with the original plot size would require six replications; however, when data were grouped into category GD1, only three replications would be needed.

Because the plot sizes used in this research are commonly used in soybean research, we expressed the convenient plot size as multiples of these basic plots. The number of replications for a given percent detectable difference at one basic plot size was compared with the LIP for each site (Table 3 ). The most convenient plot paralleled the LIP, especially when the data were grouped (GD1 and GD2), with the most convenient plot associated with smaller LIPs (Table 3). The only exception to this was in site $\mathrm{D}$ when using data from the transformed mean egg density. For example, to detect a $25 \%$ difference of the means when using the transformed egg density, the number of convenient plots for sites $\mathrm{D}$ and $\mathrm{H}$ was six and four, respectively, even though site D had a smaller LIP (1.5) than site H (1.7) (Table 3).

\section{Discussion}

The spatial distribution of SCN is affected by nematode movement and population dynamics (Gavassoni et al. 2007). Any means of moving soil with cysts containing eggs, such as runoff or flood water, wildlife, wind, and human activities such as tillage, can move SCN within and between fields. The genetics of the SCN population, the initial egg density, egg survival, edaphic factors (soil texture, $\mathrm{pH}$, etc.), and the host (genetic status, vigor, root development) affect reproduction and development of the nematode. SCN reproduces at an optimum temperature around $27^{\circ} \mathrm{C}$ (Alston and Schmitt 1988) and reproduction is greater at $\mathrm{pH} 6.5$ and 7.5 than at lower $\mathrm{pH}$ levels (Anand et al. 1995; Pedersen et al. 2010). More cysts develop on plants in disturbed than in undisturbed soils (Young 1987). H. glycines is reported to be disseminated $6.9 \mathrm{~m}$ from an infestation site in conventional and reduced tillage treatments, but only 0.5 and $1.4 \mathrm{~m}$ for no-tillage and ridge-tillage treatments (Gavassoni et al. 2007). Before cultivation, the distance between population clusters of this nematode can be only 1 to $3 \mathrm{~m}$ (Francl 1986a). There is directional spatial dependence of egg and cyst densities along soybean rows, coincident with the direction of tillage practices (Gavassoni

Table 1. Range, median, and mean of Heterodera glycines egg densities $/ 100 \mathrm{~cm}^{3}$ of soil and Lloyd's index of patchiness (LIP) for 10 field research sites ${ }^{\mathrm{x}}$

\begin{tabular}{|c|c|c|c|c|c|c|c|c|c|}
\hline \multirow[b]{2}{*}{ Site } & \multirow[b]{2}{*}{ Total sample (n) } & \multicolumn{5}{|c|}{ Egg density (eggs/100 $\mathrm{cm}^{3}$ of soil) } & \multicolumn{3}{|c|}{ LIP } \\
\hline & & Range & Mean & S.D. & Median & MMR & UD & GD1 $^{y}$ & GD2 $^{\mathbf{z}}$ \\
\hline A & 96 & 0 to 16,250 & 2,630 & 2805 & 1825 & 1.44 & 2.1 & 1.1 & 1.1 \\
\hline B & 72 & 950 to 15,700 & 5,778 & 3697 & 5175 & 1.12 & 1.4 & 1.0 & 1.0 \\
\hline $\mathrm{C}$ & 75 & 0 to 6,500 & 951 & 1452 & 350 & 2.72 & 3.3 & 1.4 & 1.4 \\
\hline $\mathrm{D}$ & 75 & 0 to 20,750 & 5,192 & 3505 & 4150 & 1.25 & 1.5 & 1.0 & 1.0 \\
\hline $\mathrm{E}$ & 40 & 1,300 to 23,350 & 7,840 & 5165 & 7025 & 1.12 & 1.4 & 1.0 & 1.0 \\
\hline $\mathrm{F}$ & 40 & 1,050 to 9,100 & 3,300 & 1699 & 2550 & 1.29 & 1.4 & 1.0 & 1.1 \\
\hline $\mathrm{G}$ & 40 & 2,200 to 25,800 & 7,659 & 4567 & 6550 & 1.17 & 1.3 & 1.0 & 1.0 \\
\hline $\mathrm{H}$ & 28 & 450 to 13,000 & 3,970 & 3350 & 2675 & 1.48 & 1.7 & 1.0 & 1.0 \\
\hline I & 28 & 1,400 to 11,250 & 3,818 & 2132 & 3325 & 1.15 & 1.3 & 1.0 & 1.0 \\
\hline $\mathrm{J}$ & 28 & 2,850 to 9,400 & 5,943 & 1803 & 6075 & 0.98 & 1.1 & 1.0 & 1.0 \\
\hline
\end{tabular}

${ }^{\mathrm{x}} \mathrm{MMR}=$ mean to median ratio and $\mathrm{UD}=$ untransformed mean egg density.

${ }^{y}$ For GD1, data were grouped into six categories of egg levels (in number of eggs/100 $\mathrm{cm}^{3}$ of soil): 0 , eggs not detected (0); 1 , very low (1 to 200$) ; 2$, low (201 to 400 ); 3 , moderate (401 to 1,200$) ; 4$, high (1,201 to 2,000); and 5, very high ( $\geq 2,001)$. The median of the egg count for each category was transformed with $\log _{10}(x+1)$.

${ }^{\mathrm{z}}$ For GD2, data were grouped into four categories of egg levels (in number of eggs $/ 100 \mathrm{~cm}^{3}$ of soil): 0 , no eggs detected (0); 1 , low (1 to 2,000); 2 , moderate (2,001 to 12,000); and 3, high $(\geq 12,001)$. The median of the egg count for each category was transformed with $\log _{10}(x+1)$. 
et al. 2007). However, egg densities commonly vary over relatively short distances within a field.

The mean egg densities in nine of the 10 research sites would be considered moderate to high levels of SCN according to the Hershman (GD1) or the Tylka scales (GD2). Thus, these sites had egg densities that would be adequate for research on the soybean-SCN interaction. However, in most sites, the egg density of SCN in one plot was generally not similar to the density in an adjacent plot. The LIPs at all but one site indicated an aggregated spatial distribution of SCN when using untransformed mean egg density. Site J was
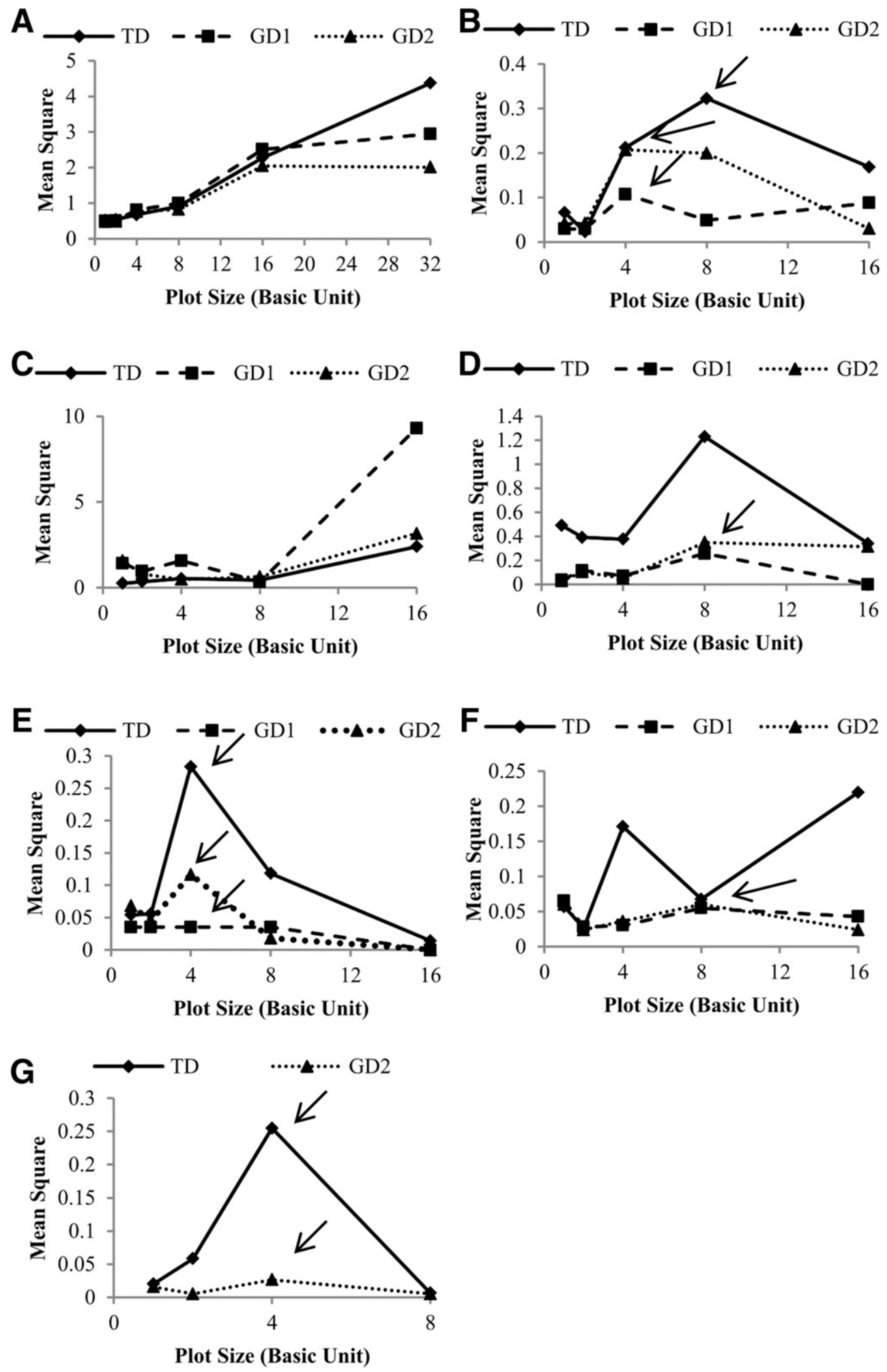

Fig. 2. A to G, Cluster sizes for plots with eggs of soybean cyst nematode in seven field experiments, respectively. For GD1, data were grouped into six categories of egg levels (in number of eggs $/ 100 \mathrm{~cm}^{3}$ of soil): 0 , eggs not detected (0); 1, very low (1 to 200); 2, low (201 to 400); 3, moderate (401 to 1,200); 4, high (1,201 to 2,000); and 5, very high ( $\geq 2,001$ ). For GD2, data were grouped into four categories of egg levels (in number of eggs $/ 100 \mathrm{~cm}^{3}$ of soil): 0 , no eggs detected $(0) ; 1$, low $(1$ to 2,000$) ; 2$, moderate $(2,001$ to 12,000$)$; and 3 , high $(\geq 12,001)$. The median of the egg count for each category was transformed with $\log _{10}(x+1)$. Arrows show peaks or local maximums in the variance. The cluster sizes are the points of plot sizes right below these peaks. To note, cluster sizes in sites $A$ and $C$ were undetected because of the peak located in the largest plot size. TD $=$ transformed mean egg density. 
the only site with a random distribution of eggs. The fact that all sites except $\mathbf{J}$ had mean numbers of eggs higher than the medians also indicated that egg densities were not normally distributed. One-half of the sites had MMRs that were very close to 1, suggesting that the egg density distribution in each of those sites was symmetric rather than skewed. Others had egg densities that were skewed to the right. The MMR and Lloyd's indices were linearly correlated and the type of data used to establish LIPs in that correlation did not have a major effect on the end results. The results of this study on spatial distribution in research plots are similar to what has been found in large fields, where densities vary from area to area and most fields have an aggregated spatial distribution of SCN (Melakeberhan et al. 2004).

The wide range of egg densities found between plots in some of these sites suggests that experimental results could be affected by the differences in egg densities and their spatial distribution within a site. For example, two plots adjacent to each other in site $\mathrm{E}$ had 20,750 and $3,150 \mathrm{eggs} / 100 \mathrm{~cm}^{3}$ of soil, respectively. That is greater

Table 2. Cluster and optimum size of plots based on Heterodera glycines spatial distribution of eggs in 10 field sites ${ }^{\mathrm{u}}$

\begin{tabular}{|c|c|c|c|c|c|c|c|c|}
\hline \multirow[b]{2}{*}{ Site } & \multirow[b]{2}{*}{ Data } & \multirow[b]{2}{*}{$\mathrm{CV}$} & \multirow[b]{2}{*}{$b^{\mathbf{v}}$} & \multirow[b]{2}{*}{$\mathbf{B}^{\mathbf{w}}$} & \multirow[b]{2}{*}{ Cluster size $^{x}$} & \multicolumn{2}{|c|}{$\begin{array}{c}\begin{array}{c}\text { Optimum } \\
\text { plot size }\left(\mathbf{m}^{2}\right)\end{array} \\
\end{array}$} & \multirow[b]{2}{*}{$r$} \\
\hline & & & & & & CVM & MCT & \\
\hline \multirow[t]{3}{*}{ A } & $\mathrm{TD}$ & 28 & 0.52 & 0.26 & ND & 28 & 28 & 0.84 \\
\hline & GD1 ${ }^{y}$ & 27 & 0.51 & 0.26 & ND & 28 & 28 & 0.82 \\
\hline & $\mathrm{GD} 2^{\mathrm{z}}$ & 26 & 0.59 & 0.29 & ND & 28 & 28 & 0.85 \\
\hline \multirow[t]{3}{*}{$\mathrm{B}$} & $\mathrm{TD}$ & 8 & 0.548 & 0.27 & 55 & 21 & 35 & 0.93 \\
\hline & GD1 & 8 & 0.87 & 0.43 & 28 & 21 & 21 & 0.86 \\
\hline & GD2 & 8 & 0.92 & 0.46 & 28 & 21 & 21 & 0.91 \\
\hline \multirow[t]{3}{*}{$\mathrm{C}$} & $\mathrm{TD}$ & 49 & 0.55 & 0.27 & ND & 27 & 45 & 0.78 \\
\hline & GD1 & 49 & 0.62 & 0.31 & ND & 27 & 45 & 0.80 \\
\hline & GD2 & 46 & 0.62 & 0.31 & ND & 27 & 45 & 0.82 \\
\hline \multirow[t]{3}{*}{$\mathrm{D}$} & $\mathrm{TD}$ & 14 & 1.24 & 0.62 & 72 & 27 & 36 & 0.70 \\
\hline & GD1 & 13 & 1.78 & 0.89 & 72 & 27 & 36 & 0.69 \\
\hline & GD2 & 13 & 1.38 & 0.69 & 72 & 27 & 36 & 0.80 \\
\hline \multirow[t]{3}{*}{ E } & $\mathrm{TD}$ & 8 & 3.04 & 1.52 & 26 & 19 & 38 & 0.52 \\
\hline & GD1 & 5 & 1.30 & 0.65 & 26 & 19 & 19 & 1.00 \\
\hline & GD2 & 6 & 1.76 & 0.88 & 26 & 19 & 19 & 0.95 \\
\hline \multirow[t]{3}{*}{$\mathrm{F}$} & $\mathrm{TD}$ & 7 & 0.58 & 0.29 & ND & 13 & 13 & 0.82 \\
\hline & GD1 & 6 & 0.72 & 0.36 & 52 & 13 & 13 & 0.83 \\
\hline & GD2 & 6 & 0.75 & 0.37 & 52 & 13 & 13 & 0.84 \\
\hline \multirow[t]{3}{*}{ G } & $\mathrm{TD}$ & 6 & 0.24 & 0.12 & 26 & 26 & 6 & 0.67 \\
\hline & GD1 & 0 & 0 & 0 & NA & NA & 6 & NA \\
\hline & GD2 & 4 & 0.64 & 0.32 & 26 & 26 & 6 & 0.77 \\
\hline \multirow[t]{3}{*}{$\mathrm{H}$} & $\mathrm{TD}$ & 12 & 2.55 & 1.28 & NA & 19 & 26 & 0.79 \\
\hline & GD1 & 10 & 2.53 & 1.27 & NA & 19 & 26 & 0.43 \\
\hline & GD2 & 10 & 2.32 & 1.15 & NA & 19 & 26 & 0.71 \\
\hline \multirow[t]{3}{*}{ I } & $\mathrm{TD}$ & 6 & 0.17 & 0.08 & NA & 19 & 6 & 0.23 \\
\hline & GD1 & 3 & 0.98 & 0.49 & NA & 19 & 6 & 0.71 \\
\hline & GD2 & 3 & 0.98 & 0.49 & NA & 19 & 6 & 0.71 \\
\hline \multirow[t]{3}{*}{$\mathrm{J}$} & $\mathrm{TD}$ & 4 & 1.42 & 0.71 & NA & NA & 19 & 0.71 \\
\hline & GD1 & 0 & 0 & 0 & NA & NA & NA & NA \\
\hline & GD2 & 0 & 0 & 0 & NA & NA & NA & NA \\
\hline
\end{tabular}

u $\mathrm{CV}=$ coefficient of variability, $\mathrm{CVM}=$ comparable variance methods, $\mathrm{MCT}=$ maximum curvature technique, $r=$ determination coefficient, $\mathrm{TD}=$ transformed mean egg density, $\mathrm{ND}=$ not determined, and $\mathrm{NA}=$ not available.

${ }^{v} b=$ estimated parameter for equation $V_{x}=V_{1} / X^{b}$, Smith's soil variability index.

${ }^{\mathrm{w}} \mathrm{B}=$ estimated parameter for equation $\mathrm{CV}_{x}=A X$.

${ }^{x}$ Cluster size in square meters.

${ }^{y}$ For GD1, data were grouped into six categories of egg levels (in number of eggs $/ 100 \mathrm{~cm}^{3}$ of soil): 0 , eggs not detected (0); 1 , very low (1 to 200); 2 , low (201 to 400); 3, moderate (401 to 1,200); 4, high (1,201 to 2,000); and 5, very high $(\geq 2,001)$. The median of the egg count for each category was transformed with $\log _{10}(x+1)$.

${ }^{\mathrm{z}}$ For GD2, data were grouped into four categories of egg levels (in number of eggs/ $100 \mathrm{~cm}^{3}$ of soil): 0 , no eggs detected (0); 1 , low (1 to 2,000); 2 , moderate $(2,001$ to 12,000$)$; and 3 , high $(\geq 12,001)$. The median of the egg count for each category was transformed with $\log _{10}(x+1)$. than a sixfold difference in egg density within a distance of $1.5 \mathrm{~m}$. Depending on the type of experimentation is being conducted, the differences in SCN spatial distribution could have a major effect on the outcome of the research. For example, when comparing cultivars for yield on SCN-infested sites, a large difference in egg density between plots could result in comparisons that are invalid because one or more cultivars were on plots with high egg densities whereas others were on plots with low densities. In sites such as A, C, and D, where very large differences existed between plots, such a situation would more likely occur. In contrast, in site J, which had a random distribution of eggs, that situation would be less likely to occur.

To illustrate the point that differences in spatial distribution of eggs could affect the outcome of experiments, consider an evaluation of soybean cultivars in site B (Fig. 1B) for yield response in the presence of SCN. Notice that there were three ranges of 24 plots each in this site. Consider two hypothetical soybean cultivars 1 and 2, each with three replications, one in each range of plots. Table 4 shows the results of what the egg densities would have been for each cultivar for each replication after conducting three separate randomizations to determine the location of each of the cultivars in the ranges. There was a difference of 3,116 eggs in the average egg density in plots between cultivar 1 and cultivar 2 in randomization 1, whereas the difference was only 433 eggs in randomization 2. However, the difference was 7,300 eggs in randomization 3 , with cultivar 2 located on plots with a much greater egg density.

Knowing the cluster size of an important factor in a field experiment is important for determining the sampling technique and

Table 3. The relationship between Lloyd's index of patchiness (LIP) and convenience plot $(\mathrm{CP})$ based on one basic plot size with probability $=0.85$ and minimal replications for soybean cyst nematode egg density data from 10 infested fields

\begin{tabular}{|c|c|c|c|c|c|c|}
\hline \multirow[b]{2}{*}{ Site $^{w}$} & \multicolumn{2}{|c|}{ TD } & \multicolumn{2}{|c|}{ GD1 $^{x}$} & \multicolumn{2}{|c|}{ GD2 $^{y}$} \\
\hline & LIP & $\mathbf{C P}^{\mathrm{z}}$ & LIP & $\mathbf{C P}$ & LIP & $\mathrm{CP}$ \\
\hline $\mathrm{J}$ & 1.1 & $3 / 10$ & 1.0 & $2 / 5$ & 1.0 & $2 / 5$ \\
\hline I & 1.3 & $7 / 10$ & 1.0 & $3 / 10$ & 1.0 & $3 / 10$ \\
\hline G & 1.3 & $4 / 15$ & 1.0 & $3 / 10$ & 1.0 & $3 / 10$ \\
\hline F & 1.4 & $3 / 20$ & 1.0 & $4 / 15$ & 1.0 & $4 / 15$ \\
\hline E & 1.4 & $3 / 20$ & 1.0 & $3 / 15$ & 1.0 & $4 / 15$ \\
\hline B & 1.4 & $6 / 15$ & 1.0 & $3 / 15$ & 1.0 & $4 / 15$ \\
\hline $\mathrm{H}$ & 1.7 & $4 / 25$ & 1.0 & $6 / 20$ & 1.0 & $5 / 20$ \\
\hline D & 1.5 & $6 / 25$ & 1.0 & $5 / 25$ & 1.0 & $5 / 25$ \\
\hline A & 2.1 & $14 / 35$ & 1.1 & $17 / 30$ & 1.1 & $16 / 30$ \\
\hline $\mathrm{C}$ & 3.3 & $23 / 45$ & 1.4 & $23 / 45$ & 1.4 & $20 / 45$ \\
\hline
\end{tabular}

${ }^{\mathrm{w}}$ Site is listed based on increasing value of LIP in the transformed mean egg density (TD) column.

x For GD1, data were grouped into six categories of egg levels (in number of eggs $/ 100 \mathrm{~cm}^{3}$ of soil): 0 , eggs not detected (0); 1 , very low (1 to 200$) ; 2$, low (201 to 400); 3, moderate (401 to 1,200); 4, high (1,201 to 2,000); and 5, very high $(\geq 2,001)$. The median of the egg count for each category was transformed with $\log _{10}(x+1)$.

${ }^{y}$ For GD2, data were grouped into four categories of egg levels (in number of eggs $/ 100 \mathrm{~cm}^{3}$ of soil): 0 , no eggs detected (0); 1 , low (1 to 2,000$) ; 2$, moderate $(2,001$ to 12,000$)$; and 3 , high $(\geq 12,001)$. The median of the egg count for each category was transformed with $\log _{10}(x+1)$.

${ }^{z}$ Numerators are the minimal replications and denominators are the percentage of the mean of difference to be detected.

Table 4. Soybean cyst nematode egg densities in research plots in field A following random assignment of two soybean cultivars to plots ${ }^{\mathrm{z}}$

\begin{tabular}{lcrrrrrrr}
\hline & \multicolumn{2}{c}{ Randomization 1 } & & \multicolumn{2}{c}{ Randomization 2 } & & \multicolumn{2}{c}{ Randomization 3 } \\
\cline { 2 - 3 } Replication & CV1 & CV2 & & CV1 & CV2 & & CV1 & CV2 \\
\hline 1 & 1,900 & 2,900 & & 3,900 & 1,450 & & 1,450 & 8,850 \\
2 & 3,950 & 2,650 & & 9,950 & 13,500 & & 2,650 & 8,750 \\
3 & 2,000 & 11,650 & & 5,600 & 3,200 & & 2,000 & 10,400 \\
Average & 2,616 & 5,733 & & 6,483 & 6,050 & & 2,033 & 9,333 \\
\hline
\end{tabular}

${ }^{\mathrm{z}}$ Values are presented as the number of eggs $/ 100 \mathrm{~cm}^{3}$ of soil. $\mathrm{CV}=$ cultivar. 
choosing the most appropriate experimental design (Madden and Hughes 1999). Furthermore, it has been demonstrated that knowing the cluster size can help produce more accurate estimates of treatment effects (Hau et al. 1982; Ojiambo and Scherm 2010; Smith et al. 1995). In five of the sites, the cluster sizes were up to four times the size of an individual plot, suggesting that smaller blocks should be used or that a different design (e.g., incomplete blocks) should be used. At site B, however, the cluster size was determined to be $55 \mathrm{~m}^{2}$ (eight basic units). In a field with a small cluster, one could reduce the size of the blocks and position them in a way that facilitates proper evaluation of the treatments or simply change the design. In a site with larger clusters, like site B, one could actually group treatments in clusters with different levels of the pathogen. Furthermore, the identification of cluster size considers not only the value of each datum (e.g., egg population density) but its location within a field as well. This is an advantage over the use of indices like LIP and MMR.

In this research, the optimum plot size and plot number (replications) for each site were calculated using data from three different sources: from the direct egg counts and from data generated by classifying egg counts into two different category groups. The purpose of this exercise was to design plots where differences in egg density would be minimal and find the least number of replications required to conduct an experiment at the site. Because of the marked aggregated distribution of $\mathrm{SCN}$ at sites $\mathrm{A}$ and $\mathrm{C}$, a difference as much as $35 \%$ of the means would likely not be detected using one standard plot size and four or five replications. In other sites, such as site D, differences as much as $25 \%$ of the means of two treatments would only be detected with at least six replications. In contrast, in site J, a difference as low as $10 \%$ of the means would be detected with only three replications.

The two category groups by Hershman (2010) and Tylka (2012) were used because they attempted to group egg densities into no risk or low, moderate, or high risk for soybean yield loss. When data were grouped into the two category groups (GD1 and GD2), all LIPs were reduced, with most slightly $>1$. The use of biological meaningful categories therefore reduced the perceived level of SCN aggregation and the differences among and within sites were reduced. The use of categorical data also reduced the optimum number of replications, but not the optimum plot size. The use of these types of categories could assist in the design of field experiments with SCN. Since most plot work with soybean and SCN would most likely be measuring yield as one criterion of the effects of SCN, these categories may have utility in deciding the number of replications. Using the two categories, however, depends on the accuracy of the egg thresholds within these categories to result in damage to soybean yield.

There is currently no region-wide predictive equation for yield loss based on initial nematode populations densities in the soil (Donald et al. 2006; Niblack et al. 1992; Rincker et al. 2017; Young 1998). Actual yields attained at specific SCN levels may vary as a result of the occurrence of other stresses, such as pests, drought, temperature, herbicide injury, and so on. There has, however, been considerable research on the effect of SCN on yield losses in soybean, and the results vary from state to state and from year to year. Egg densities of approximately $\geq 1,000 \mathrm{eggs} / 100 \mathrm{~cm}^{3}$ of soil are reported to have considerable impact on soybean yield. An initial population of 1,200 juveniles of $H$. glycines per pot caused a reduction of the top dry weight and grain yield of soybean (Asmus and Ferraz 2002). Yield reductions of 52 and $19 \%$ were measured in Iowa when susceptible cultivars were inoculated with $1,250 \mathrm{eggs} / 100 \mathrm{~cm}^{3}$ of soil in 1986 and 1987, respectively (Niblack et. al. 1992). Resistant cultivars in Minnesota produced greater yield by 23 and $28 \%$ compared with susceptible cultivars when egg density at planting was $>700$ and 5,000 eggs $/ 100 \mathrm{~cm}^{3}$ of soil, respectively (Chen et al. 2001).

Determining the egg threshold for a yield reduction has been challenging. In microplot field experiments, Niblack et. al. (1992) showed that the damage threshold of susceptible cultivars was as low as 10 to $50 \mathrm{eggs} / 100 \mathrm{~cm}^{3}$ of soil. Other research, however, reported no difference in yield was observed between resistant and susceptible cultivars at sites where egg density at planting was lower than $500 \mathrm{eggs} / 100 \mathrm{~cm}^{3}$ of soil (Chen et al. 2001). Furthermore, healthy crops are capable of compensating for some SCN damage; thus there may be no or minor yield loss at low SCN egg densities (Hershman 2010).

The effect of the spatial distribution of SCN on field experiments would likely be less of a concern if resistant cultivars compared with susceptible cultivars were being used. Since resistant cultivars could withstand a range of egg densities without damage (Rincker et al. 2017), differences in egg densities between plots may result in little effect on the outcome of the experiment. However, when using susceptible cultivars, differences in egg densities between plots could be important factors in the results. When the susceptibility of cultivars is known, grouping data into the two category groups may be an appropriate method of examining data to establish the minimum plot size and number of replications that meet the objective of the research.

The results of this study show that spatial distribution of eggs in SCN research sites can vary greatly within and among sites and corroborate the findings of Francl (1986a) and Pérez-Hernández and Giesler (2017). Since egg density is known to affect the soybean-SCN interaction, the spatial distribution of eggs should be considered an important factor when conducting field experiments. This was also emphasized by Pérez-Hernández and Giesler (2017) with SCN research in Nebraska. Researchers tend to use small plots for field experiments because inputs and cost are reduced compared with larger plots. However, the data in this study suggest that the plot sizes used were too small to minimize the differences in spatial distribution. In some sites it might have been impractical to conduct field experiments with SCN and soybean using the plot sizes suggested by the analysis. Not only would the individual plots be extremely large, but the area required for a field site could be exceedingly large depending on how many treatments were evaluated.

Most researchers who evaluate cultivars for yield on SCN-infested sites conduct multiple field trials in different locations, thus reducing the potential impact of differences in spatial distribution among plots on the outcome of the evaluation. However, in other types of experimentations not conducted at multiple locations, the differences in egg densities between plots could have a major effect on the outcome of the experiments. It may be impractical for many researchers to sample each plot to determine egg densities before conducting experiments on SCN-infested soil. However, knowledge of the large differences in SCN egg densities that can occur between plots may help researchers mitigate this potential problem in field experiments. Increasing replications and conducting experiments on multiple sites are likely the most practical methods to reduce the variability attributable to differences in the spatial distribution of $H$. glycines.

\section{Acknowledgments}

We thank Tracy Christianson for technical assistance.

\section{Literature Cited}

Allen, T. W., Bradley, C. A., Sisson, A. J., Byamukama, E., Chilvers, M. I., Coker, C. M., Collins, A. A., Damicone, J. P., Dorrance, A. E., Dufault, N. S., Esker, P. D., Faske, T. R., Giesler, L. J., Grybauskas, A. P., Hershman, D. E., Hollier, C. A., Isakeit, T., Jardine, D. J., Kelly, H. M., Kemerait, R. C., Kleczewski, N. M., Koenning, S. R., Kurle, J. E., Malvick, D. K., Markell, S. G., Mehl, H. L., Muller, D. S., Mueller, J. D., Mulrooney, R. P., Nelson, B. D., Newman, M. A., Osborne, L., Overstreet, C., Padgett, G. B., Phipps, P. M., Price, P. P., Sikora, E. J., Smith, D. L., Spurlock, T. N., Tande, C. A., Tenuta, A. U., Wise, K. A., and Wrather, J. A. 2017. Soybean yield loss estimates due to disease in the United States and Ontario, Canada, from 2010 to 2014. Plant Health Prog. 18:19-27.

Alston, D. G. and Schmitt, D. P. 1988. Development of Heterodera glycines life stages as influenced by temperature. J. Nematol. 20:366-372.

Anand, S. C., Matson, K. W., and Sharma, S. B. 1995. Effect of soil temperature and $\mathrm{pH}$ on resistance of soybean to Heterodera glycines. J. Nematol. 27:478-482.

Asmus, G. L., and Ferraz, L. C. C. B. 2002. Effect of population densities of Heterodera glycines race 3 on leaf area, photosynthesis and yield of soybean. Fitopatol. Bras. 27:273-278.

Bradley, C. A., Biller, C. R., and Nelson, B. D. 2004. First report of soybean cyst nematode (Heterodera glycines) on soybean in North Dakota. Plant Dis. 88:1287.

Campbell, C. L., and Madden, L. V. 1990. Introduction to Plant Disease Epidemiology. Wiley and Sons, New York, NY.

Chen, S. Y., Porter, P. M., Orf, J. H., Reese, C. D., Stienstra, W. C., Young, N. D., Walgenbach, D. D., Schaus, P. J., Arlt, T. J., and Breitenbach, F. R. 2001. 
Soybean cyst nematode population development and associated soybean yields of resistant and susceptible cultivars in Minnesota. Plant Dis. 85:760-766.

Donald, P. A., Pierson, P. E., St. Martin, S. K., Sellers, P. R., Noel, G. R., MacGuidwin, A. E., Faghihi, J., Ferris, V. R., Grau, C. R., Jardine, D. J., Melakeberhan, H., Niblack, T. L., Stienstra, W. C., Tylka, G. L., Wheeler, T. A., and Wysong, D. S. 2006. Assessing Heterodera glycines-resistant and susceptible cultivar yield response. J. Nematol. 38:76-82.

Duan, Y. X., Zheng, Y. N., Chen, L. J., Zhou, X. M., Wang, Y. Y., and Sun, J. S. 2009. Effects of abiotic environmental factors on soybean cyst nematode. Agric. Sci. China 8:317-325.

Francl, L. J. 1986a. Spatial analysis of Heterodera glycines populations in field plots. J. Nematol. 18:183-189.

Francl, L. J. 1986b. Improving the accuracy of sampling field plots for plantparasitic nematodes. J. Nematol. 18:190-195.

Gavassoni, W. L., Tylka, G. L., and Munkvold, G. P. 2001. Relationships between tillage and spatial patterns of Heterodera glycines. Phytopathology 91:534-545.

Gavassoni, W. L., Tylka, G. L., and Munkvold, G. P. 2007. Effects of tillage practices on dissemination and spatial patterns of Heterodera glycines and soybean yield. Plant Dis. 91:973-978.

Hatheway, W. H. 1961. Convenient plot size. Agron. J. 53:279-280.

Hau, F. C., Campbell, C. L., and Beute, M. K. 1982. Inoculum distribution and sampling methods for Cylindrocladium crotalariae in a peanut field. Plant Dis. 66:568-571.

Hershman, D. E. 2010. 2010. Soybean cyst nematode (SCN) management recommendations for Kentucky. Plant Pathology Fact Sheet PPFS-AG-S-24. University of Kentucky Cooperative Extension Service, Lexington.

Keller, K. R. 1949. Uniformity trial on hops (Humulus lupulus L.) for increasing the precision of field experiments. Agron. J. 41:389-392.

Kulkarni, S. S., Bajwa, S. G., Rupe, J. C., and Kirkpatrick, T. L. 2008. Spatial correlation of crop to soybean cyst nematode (Heterodera glycines). Trans. ASABE 51:1451-1459.

Leilah, A. A., and Al-Barrak, K. M. 2005. Estimation of optimum field plot size and shape and number of replicates in sorghum yield trials. J. King. Saud. Univ. 17:101-116.

Lloyd, M. 1967. Mean crowding. J. Anim. Ecol. 36:1-30.

Madden, L. V., and Hughes, G. 1999. Sampling for plant disease incidence. Phytopathology 89:1088-1103.

Melakeberhan, H., Avendaño, F., and Pierce, F. 2004. Spatial analysis of soybean yield in relation to soil texture, soil fertility and soybean cyst nematode. Nematology 6:527-545.
Niblack, T. L. 2005. Soybean cyst nematode management reconsidered. Plant Dis 89:1020-1026.

Niblack, T. L., Baker, N. K., and Norton, D. C. 1992. Soybean yield losses due to Heterodera glycines in Iowa. Plant Dis. 76:943-948.

Ojiambo, P. S., and Scherm, H. 2010. Efficiency of adaptive cluster sampling for estimating plant disease incidence. Phytopathology 100:663-670.

Pedersen, P., Tylka, G. L., Mallarino, A., MacGuidwin, A. E., Koval, N. C., and Grau, C. R. 2010. Correlation between soil pH, Heterodera glycines population densities, and soybean yield. Crop Sci. 50:1458-1464.

Pérez-Hernández, O., and Giesler, L. J. 2017. Intra- and interplot variability of Heterodera glycines population densities in experimental setting to soybean variety evaluations in Nebraska. Crop Prot. 94:123-136.

Poromarto, S., del Rio Mendoza, L. E., and Nelson, B. D. 2011. Spatial distribution of soybean cyst nematode in research plots. Phytopathology 101:S144.

Poromarto, S. H., and Nelson, B. D. 2009. Reproduction of soybean cyst nematode on dry bean cultivars adapted to North Dakota and northern Minnesota. Plant Dis. 93:507-511.

Poromarto, S. H., and Nelson, B. D. 2010. Evaluation of northern-grown crops as hosts of soybean cyst nematode. Online. Plant Health Prog. 11:24.

Riggs, R. D., and Hamblen, M. L. 1962. Soybean cyst nematode studies in the family Leguminosae. Ark. Agr. Exp. Sta. Rep. Ser. 110:1-8.

Rincker, K., Cary, T., and Diers, B. W. 2017. Impact of soybean cyst nematode resistance on soybean yield. Crop Sci. 57:1373-1382.

Smith, D. R., Conroy, M. J., and Brakhage, D. H. 1995. Efficiency of adaptive cluster sampling for estimating density of winter waterfowl. Biometrics 51: 777-788.

Tylka, G. L. 2012. Soybean Cyst Nematode Field Guide, 2nd ed. Extension Publication CSIO012. Iowa State University, Ames.

Tylka, G. L., and Marett, C. C. 2017. Known distribution on the soybean cyst nematode, Heterodera glycines, in the United States and Canada, 1954 to 2017. Plant Health Prog. 18:167-168.

U.S. Department of Agriculture. 2019. National Agricultural Statistics Service Statistics by Subject. https://www.nass.usda.gov/Statistics_by_Subject/index.php?sector=CROPS

Winstead, N. N., Skotland, C. B., and Sasser, J. N. 1955. Soybean-cyst nematode in North Carolina. Plant Dis. Rep. 39:9-11.

Young, L. D. 1987. Effects of soil disturbance on reproduction of Heterodera glycines. J. Nematol. 19:141-142.

Young, L. D. 1998. Influence of soybean cropping sequences on seed yield and female index of the soybean cyst nematode. Plant Dis. 82:615-619. 